Originally published as:

Rumer, L., Sheshukova, O., Dautel, H., Mantke, O.D., Niedrig, M.

Differentiation of medically important Euro-Asian tick species ixodes ricinus, ixodes persulcatus, ixodes hexagonus, and dermacentor reticulatus by polymerase chain reaction (2011) Vector-Borne and Zoonotic Diseases, 11 (7), pp. 899-905.

DOI: 10.1089/vbz.2009.0191

This is a copy of an article published in the Vector-Borne and Zoonotic Diseases (@ 2011 copyright Mary Ann Liebert, Inc.;

Vector-Borne and Zoonotic Diseases is available online at: http://online.liebertpub.com 


\title{
Differentiation of Medically Important Euro-Asian Tick Species Ixodes ricinus, Ixodes persulcatus, Ixodes hexagonus, and Dermacentor reticulatus by Polymerase Chain Reaction
}

\author{
Leonid Rumer, ${ }^{1}$ Olga Sheshukova, ${ }^{1}$ Hans Dautel, ${ }^{2}$ Oliver Donoso Mantke, ${ }^{1}$ and Matthias Niedrig ${ }^{1}$ \\ ${ }^{1}$ Robert Koch-Institute, Centre for Biological Safety (ZBS 1), Berlin, Germany. \\ ${ }^{2}$ IS Insect Services GmbH, Berlin, Germany. \\ Address correspondence to: \\ Leonid Rumer \\ Robert Koch-Institute \\ Centre for Biological Safety (ZBS 1) \\ Nordufer 20 \\ $D-13353$ Berlin \\ Germany \\ E-mail: rumerl@rki.de
}

\begin{abstract}
Understanding epidemiology of the tick-borne pathogens requires the accurate identification of the vector ticks. Morphological analysis of ticks is difficult and often leads to misidentification. Molecular techniques offer an alternative approach of tick identification. To date, no practical and reliable molecular assays for discrimination of Euro-Asian ticks are available. Our aim was to develop such an assay for discrimination between four Euro-Asian tick species of high medical importance such as Ixodes ricinus, Ixodes persulcatus, Ixodes hexagonus, and Dermacentor reticulatus. As a basis, we have chosen conventional species-specific polymerase chain reaction (PCR), a technique providing a good combination of simplicity and reliability. The DNA information available on ticks was searched for orthologous loci containing stretches of sequence dissimilarity sufficient for designing species-specific primers. ITS2 locus (second internal transcribed region of the rRNA gene cluster) was found to be the most favorable for primer design. Finally, for each of the three Ixodes species a PCR was developed amplifying only for the targeted species. One PCR amplified the entire ITS2 locus of the four species and allowed discrimination of $D$. reticulatus from the Ixodes species on the basis of the size difference of the respective PCR products. This PCR system was successfully tested for discrimination of the ticks at different maturation stages (larva, nymph, and adult) in engorged and unfed conditions, and therefore it may be useful for large-scale epidemiological studies. Differentiation between the closely related I. ricinus and I. persulcatus, the two species most often occurring in the tick-borne diseases in Eurasia, is of special importance.
\end{abstract}

\section{Introduction}

Causative agents of many important human and animal diseases are transmitted by ticks (Brown et al. 2005, Estrada-Pena 2009). Different tick species prevail in different geographic regions. To understand the epidemiology of tick-borne pathogens and develop effective approaches for control and prevention of the related diseases, an accurate identification of the vector ticks is important.

Morphological analysis based on a system of phenotypic criteria (Keirans and Litwak 1989, Sonenshine 1991) has long been a customary way of tick determination. However, the morphological identification is difficult, not always possible, and may lead to misidentification (Caporale et al. 1995, Poucher et al. 1999, Anderson et al. 2004, and references therein). Adult ticks belonging to different genera are most easily identified using dichotomous keys, but even in this situation a solid training and experience in taxonomy and morphology is required. Subadult isolates (nymphs and larvae) are usually more difficult to identify, particularly in closely related species, where distinguishing 
characteristics can show high intraspecific variability and may overlap with those of the related species. Moreover, even at an intergeneric level morphological identification is poorly applicable in the case of damaged ticks.

More convenient and reliable approaches that are free from the discussed disadvantages are desirable. Apparent opportunities are offered by molecular techniques. Sequencing-based analysis of well-known nuclear and mitochondrial markers has been used for phylogenetic studies of ticks (Black and Piesman 1994, Caporale et al. 1995, Black et al. 1997, Mangold et al. 1998, Fukunaga et al. 2000, Murrell et al. 2001b, 2003, Nava et al. 2009), investigation of tick population structure (Casati et al. 2008), and solution of the conspecificity problem in morphologically very similar species (Wesson et al. 1993, Zahler et al. 1995). In particular, the genes of the rRNA gene cluster (18S, 28S, and 5S), internal transcribed spacer 2 (ITS2) (Fig. 1), separating the 5S and 28S rDNA genes, mitochondrial $16 S$ and $12 S$ rDNA genes, and some other mitochondrial genes were used in these studies.

However, epidemiological surveillance even in small geographic areas usually involves large numbers of tick isolates and therefore appeals for rapid and at the same time reliable identification method. Polymerase chain reaction-restriction fragment length polymorphism (PCR-RFLP) has been previously used for this purpose. In particular, a taxonomic key based on the PCR-RFLP of ITS2 locus was developed for distinction of 17 Ixodes tick species typical for the United States (Poucher et al. 1999). PCR-RFLP of mitochondrial 16S rRNA gene was used for discrimination on the genus level of medically important U.S. Metastriata ticks (Anderson et al. 2004).

In the later studies, however, the species-specific PCR was proposed as more convenient and reliable approach. On the basis of the ITS2 sequence, species-specific real-time PCR assays were developed for differentiation between four U.S. tick species of high medical importance, including the closely related Ixodes scapularis and Ixodes pacificus (Shone et al. 2006). For discrimination of two other important North American species, Dermacentor andersoni and Dermacentor variabilis, a conventional PCR-based assay taking the advantage of the length difference of their ITS2 was developed (Dergousoff and Chilton 2007).

To date, there are no practical and effective molecular assays for discrimination of tick species in Euro-Asia. To establish the species-specific, PCR-based system for differentiation of Euro-Asian ticks, we report here a series of species-specific PCRs, discriminating between four tick species of high medical importance in Europe and Asia, namely, Ixodes ricinus, Ixodes persulcatus, Ixodes hexagonus, and Dermacentor reticulatus.

I. ricinus and $I$. persulcatus are considered the most abundant and medically significant Euro-Asian tick species responsible for the majority of tick-transmitted diseases in Europe and Asia (Brown et al. 2005). They are the main vectors of tick-borne encephalitis virus and Lyme disease Borrellia. $I$. persulcatus dominates in the Asian Taiga regions, while I. ricinus prevails in the temperate parts of Europe. The exact Eastern European distribution ranges of either species are not quite clear and the area of their coexistence is not precisely determined. According to Pomerantzev (1959) and the maps of Kolonin (1981), the eastern distribution of $I$. ricinus covers the Eastern European states, including parts of Western Russia up to a line connecting the Karel Peninsula, the St. Petersburg, and Gorki area and further south along the Volga River, whereas the western boundary of $I$. persulcatus crosses the Baltic States and the western parts of Russia. The authors cite single findings of $I$. ricinus east of the Volga River as well as of $I$. persulcatus west of the described area. However, the existence of established populations has not been confirmed, except the Kokkola Islands in Finland, where an $I$. persulcatus population has been detected far west of its known distribution range (Jääskeläinen et al. 2006). Currently, coexistence of the two species has been reported from the western parts of Russia and the Baltic States (Bormane et al. 2004, Brown et al. 2005, Masuzawa et al. 2005). Some studies indicate the extension of $I$. ricinus up to Ural Mountains (Schwarz et al. 2009 and references therein).

I. hexagonus is ranked by various studies as the second most prevalent Ixodes species in Europe after I. ricinus (Camacho et al. 2003, Nijhof et al. 2007). Its role in transmission of zoonotic diseases has not been yet rigorously studied, but the presence of pathogens also found in $I$. ricinus has been established, and in some cases the prevalence of pathogens was higher than in I. ricinus (Camacho et al. 2003). 
$D$. reticulatus extends from Western Europe up to Central Asia and is an important vector of canine babesiosis, tularaemia, Q-fever, and at least one zoonotic rickettsiosis (Dautel et al. 2006).

\section{Materials and Methods}

\section{Tick material}

Ticks were obtained from the IS Insect Services GmbH (Berlin, Germany). Adult I. ricinus, I. persulcatus, and $D$. reticulatus ticks were fed on rabbits; adult engorged I. hexagonus were obtained from a hedgehog. All larval and nymphal ticks were fed on gerbils (Meriones unguiculatus). Ticks were kept at $20^{\circ} \mathrm{C}$ and $90 \%$ relative humidity (r.h.) either at darkness or under long day conditions $(16 \mathrm{~h}$ light and $8 \mathrm{~h}$ darkness) between blood meals. I. ricinus and $D$. reticulatus ticks originated from the Berlin area and were the F1 and F3 laboratory generation, respectively. I. persulcatus (F4 laboratory generation) originated from Lithuania and I. hexagonus (F1 generation) from the Karlsruhe and Berlin area. Four unfed adult females and four fed nymphs of each species and two fed larvae of both $I$. persulcatus and $D$. reticulatus were used in PCRs.

In addition, the following unfed field ticks collected by Dr. Elmara Graser (Analytikjena Bio Solutions, Jena, Germany) and Dr. Thomas Talaska (consulting physician for microbiology) from Berlin/Brandenburg region were used: nine I. ricinus (including three females, three Rickettsia-infected females, and three Borrelia-infected nymphs), two female I. hexagonus, and eight female $D$. reticulates (including four Ricketsia infected).

The species identity of the Ixodes ticks was validated by sequencing of the mitochondrial 16S RNA fragment generated by PCR 5 (Table 1; Caporale et al. 1995).

Each tick was frozen and stored at $-70^{\circ} \mathrm{C}$ until use.

\section{DNA isolation}

Total tick DNA was isolated from the complete tick body by homogenization by the rapideStripe tick DNA/RNA Extraction Kit (Analytikjena Bio Solutions). Briefly, an individual tick was placed into the Lysis Tube $\mathrm{P}, 100 \mu \mathrm{L}$ of the RL solution was added, and homogenization was performed in the SpeedMill during $4 \mathrm{~min}$. The DNA was extracted and purified with the rapideStripe tick DNA/RNA Extraction Kit, according to the recommendations of the manufacturer. DNA was eluted with $100 \mu \mathrm{L}$ of the elution buffer and stored at $-20^{\circ} \mathrm{C}$.

\section{Primers, PCRs, and analysis of PCR results}

All primers (Table 1) were synthesized by Invitrogen GmbH (Karlsruhe, Germany). Analytical PCRs were performed in a total volume of $10 \mu \mathrm{L}$. Amplicons for DNA sequencing were obtained in $50 \mu \mathrm{L}$. PCR mixtures were prepared as follows: $0.05 \mathrm{U} / \mu \mathrm{L}$ of AmpliTaq polymerase, $1 \times$ PCR Buffer, $1.5 \mathrm{mM}$ $\mathrm{MgCl}_{2}$ (all from Invitrogen $\mathrm{GmbH}$ ), $0.2 \mathrm{mM}$ of each dNTP (Fermentas $\mathrm{GmbH}$, St. Leon-Rot, Deutschland), $0.5 \mathrm{pm} / \mu \mathrm{L}$ of each primer, and fourfold (adult ticks) or twofold (subadult forms) dilution of DNA preparation was added 1:10 to the final volume. Reactions were performed in thermal cycler Biometra (Biometra Biomedizinische Analytik GmbH, Goettingen, Germany) with the following conditions: $94^{\circ} \mathrm{C}, 3 \mathrm{~min}$ (initial denaturation); 35 cycles of $94^{\circ} \mathrm{C}, 40 \mathrm{~s}$ (denaturation), annealing by the respective temperature (depending on the primer pair, Table 1), $60 \mathrm{~s}$, and $72^{\circ} \mathrm{C}, 60 \mathrm{~s}$ (extension); followed by $72^{\circ} \mathrm{C}$ for 10 min (final extension). Negative controls were included in each PCR run.

PCRs were analyzed by electrophoresis in $2 \%$ agarose-TBE gel, containing $0.5 \mu \mathrm{g} / \mathrm{mL}$ ethidium bromide. A 100 bp DNA ladder (Invitrogen $\mathrm{GmbH}$ ) was used as the size standard.

The identity of PCR amplicons was confirmed by their direct sequencing after gel extraction and purification with QIAquick Gel Extraction kit (Qiagen GmbH, Hilden, Germany). 
$\mathrm{GmbH}$ ) according to the manufacturer's recommendations. Plasmid DNA was isolated from transformants with Qiagen plasmid DNA purification Kit (Qiagen $\mathrm{GmbH}$ ), and the insert was sequenced using M13 forward and reverse primers.

\section{DNA sequencing}

Automated DNA sequencing (ABI PRISM DNA Sequencer) in both directions with the respective primers was performed in all cases.

ITS2 sequences were deposited in GenBank under the accession numbers GU001676-GU001679 and GQ924083.

\section{Bioinformatics tools}

DNA Star (Lasergene) package and the tools offered by NCBI were utilized for DNA search and analysis. In particular, primer design and analysis of the sequencing traces were performed by the respective tools offered by DNA Star package. Multiple alignment was performed by ClustalW method (within the DNA Star package), and for pair-wise alignment bl2seq2 tool (NCBI) was also used. The specificity of PCR primer pairs to the intended templates was checked with the Primer-BLAST tool $(\mathrm{NCBI})$.

\section{Results}

\section{Choice of the locus for primer design}

DNA database was searched for an orthologous locus whose sequence variablity among the targeted tick species was sufficient for a design of the species discriminating PCRs. Most of the sequence information was related to the ITS2 or mitochondrial DNA. Either of these two loci is conserved at the intraspecies level and displays noticeable interspecies variability. Moreover, each of these loci is present in multiple copies in the genome, which is favorable for their yield in DNA preparations. Both loci have been extensively used in phylogenetic studies as well as in all previous works on PCR-based tick differentiation.

Complete ITS2 sequence was available for 7 and 15 isolates of $I$. ricinus and $I$. Persulcatus, respectively (Fukunaga et al. 2000). Additionally, one partial sequence lacking 54 bp on the 5 '-end was submitted by Chitimia et al. (2009) for I. ricinus. For I. hexagonus, however, no ITS2 sequences were entered. Entire mitochondrial genome was available for I. persulcatus and I. hexagonus (Shao et al. 2005 ) but for $I$. ricinus only single fragments of mitochondrial DNA were known.

The entire length of the overall very similar mitochondrial DNAs of $I$. persulcatus and $I$. hexagonus yielded only a few dissimilar stretches convenient for the PCR design. At the same time the available mitochondrial DNA fragments of $I$. ricinus were highly similar to the corresponding fragments of the $I$. persulcatus, and our attempts to sequence the missing part of $I$. ricinus mitochondrial DNA by primer walking were unsuccessful (data not shown). On the basis of the available mitochondrial sequences, we successfully developed discriminating PCRs for the pairs $I$. hexagonus/l. ricinus, and $I$. hexagonus/l. persulcatus, but not for the pair I. ricinus/l. persulcatus.

Discrimination between I. ricinus and I. persulcatus was the main focus of this work. Therefore, we attempted to establish the discrimination system on the basis of ITS2.

\section{Discrimination between $I$. ricinus and $I$. persulcatus}

The ITS2 sequences of $I$. persulcatus and $I$. ricinus deposited in DNA data bank were from ticks collected in Japan and former Czechoslovakia, respectively (Fukunaga et al. 2000). The partial $I$. ricinus sequence was from a Romanian specimen (Chitimia et al. 2009). Within each of the two tick species the similarity value was $97.2 \%$ for $I$. ricinus and $99 \%$ for $I$. pesulcatus (Fukunaga et al. 2000). To derive the ITS2 sequences of our I. ricinus/I. persulcatus ticks for comparison with the available ones, we developed a PCR amplifying the entire ITS2 locus (PCR 1, Table 1). The direct and reverse primers of this PCR targeted, respectively, the left and the right ITS2 flanking fragment sequenced by Fukunaga et al. (2000) concomitantly with the ITS2. The left fragment belongs to the 5S rRNA gene 
and the right one to the 28S rRNA gene (Fig. 1). Both fragments are highly conserved among the Ixodes species. This PCR yielded the expected amplicon of about $778 \mathrm{bp}$ for the specimens of both species.

The amplicons from three specimens of each species were cloned and sequenced. The sequences fit well into the range of the intraspecies sequence variation of either species estimated by Fukunaga et al. (2000).

Multiple alignments of all ITS2 sequences discussed above were performed to search for the fragments of sequence dissimilarity appropriate for design of the species-differentiating PCR. A part of this alignment is presented on the Figure 1 . In closely similar ITS2 of the two species (identity $87.4 \%-$ $88.9 \%$ depending on the pair of the isolates) the stretches of dissimilarity were rather homogenously distributed along the entire length of the ITS2 locus. The alignment revealed no deletions/insertions long enough for a design of a single PCR discriminating by the amplicon size (Dergousoff and Chilton 2007, Chitimia et al. 2009). Therefore, we decided to develop one specific PCR for each of the two species. For this purpose we looked for the stretches of interspecies dissimilarity with the highest degree of intraspecies conservation, especially in the vicinity of the 3 '-end of the probable primer sequence.

A few dissimilarity stretches that fit these criteria and allowed at the same time to design good-qualityspecific primers and their counterparts were found for each species and the PCRs generated on their basis were tested. For either species we found a set of PCRs stably yielding the expected product only for the targeted species. Finally, we selected one primer pair for each species (Table 1, PCR 2 and PCR 3; Fig. 1), which unlike the other ones did not yield satellite products (Fig. 2). The optimal annealing temperatures of the two PCRs were, however, essentially different (Table 1). We therefore selected one more I. ricinus-specific pair (PCR 2a, Table 1 and Fig. 2) that allows performing the reaction at the annealing temperature equal to that of the I. persulcatus-specific PCR (PCR 3), but displays in some cases a pattern of week satellite products on I. persulcatus template. However, these satellite products did not hamper the discrimination since they were significantly longer than the targeted PCR 2a amplicon.

These PCRs yielded no product on $I$. hexagonus and $D$. reticulatus.

\section{Specific PCR for I. hexagonus}

PCR 1 also yielded a product on the DNA of I. hexagonus (Fig. 2). The I. hexagonus amplicon was close in length to that of $I$. ricinus/l. persulcatus, which is the characteristic size of ITS2 of the Ixodes species (Fukunaga et al. 2000). The amplicons from five specimens were cloned and sequenced. The similarity range was between $99.9 \%$ and $100 \%$.

Identity of $I$. hexagonus ITS2 with that of $I$. ricinus and $I$. persulcatus was $59.7 \%-60.9 \%$ and $59.0 \%-$ $59.6 \%$, respectively. On the basis of the low similarity, a set of primer pairs, each containing at least one primer, targeting within a stretch of high dissimilarity with the two other Ixodes species was generated and tested in PCRs. All primer pairs yielded the expected product only for I. hexagonus. The pair of PCR 4 (Table 1) was selected for routine analysis.

Each of the designed species-specific PCRs was also checked for specificity by Primer-BLAST tool (NCBI) against all available DNA databases. Analysis revealed that each PCR targeted exclusively the intended template.

\section{Intergeneric PCR}

The PCR 1 on $D$. reticulatus yielded the amplicon with the size of about $1045 \mathrm{bp}$, which differs distinctively from the respective amplicons of Ixodes (Fig. 2). Therefore, PCR 1 can also distinguish $D$. reticulatus from the three Ixodes species. However, in the areas of $D$. reticulatus distribution tick species, with ITS2 length similar to that of $D$. reticulatus could also be present (Zahler et al. 1995, Murrell et al. 2001a, Chitimia et al. 2009). 


\section{Discussion}

A specific task of tick differentiation often stipulates in advance the set of ticks of interest and/or implies knowledge of the species prevailing in the surveillance areas. For each of the targeted species a PCR-based discrimination system should have at least one primer pair yielding the respective product only for this species. At the same time the optimal system should also reliably cut off other species concomitantly existing or emerging in the given area. During relatively short time the geographic distribution of species can drastically change. For example, in the last three decades $D$. reticulatus has essentially expanded its range in the eastern and southwestern parts of Germany and I. ricinus shifted north (Dautel et al. 2006, Gray et al. 2009). Minor tick species, imported by migrating birds, can deliver important pathogens (Pietzsch et al. 2008). Specimens featuring the negative outcome for each of the specific PCRs of a given discrimination system may provide important information on the trends in the species dynamics. A species-specific PCR should therefore be unique for the targeted species not only within a limited group of tick species under consideration but also for the entire variety of tick species. The proposed system for discrimination of the four Euro-Asian tick species, along with the previously developed systems, may establish the first basis of a global PCRbased tick identification framework, complementing the conventional morphological systems.

\section{Acknowledgments}

We thank Jasmin Skuballa, University of Karlsruhe, Germany, for providing fed adults of $I$. hexagonus; Dr. Yuliya Dobrydneva and Dr. Regina Schädler for reading and correcting the article; and all members of Dr. Niedrig unit for support.

\section{Disclosure Statement}

No competing financial interests exist.

\section{References}

Anderson, JM, Ammerman, NC, Norris DE. Molecular differentiation of metastriate tick immatures. Vector Borne Zoonot Dis 2004; 4:334-342.

Black, WC 4th, Klompen, JS, Keirans, JE. Phylogenetic relationships among tick subfamilies (Ixodida: Ixodidae: Argasidae) based on the 18S nuclear rDNA gene. Mol Phylogenet Evol 1997; 7:129-144. Black, WC 4th, Piesman, J. Phylogeny of hard- and soft-tick taxa (Acari: Ixodida) based on mitochondrial 16S rDNA sequences. Proc Natl Acad Sci USA 1994; 91:10034-10038.

Bormane, A, Lucenko, I, Duks, A, Mavtchoutko, V, et al. Vectors of tick-borne diseases and epidemiological situation in Latvia in 1993-2002. Int J Med Microbiol 2004; 293, Suppl 37:36-47. Brown, RN, Lane, RS, Dennis, DT. Geographic distributions of tick-borne diseases and their vectors. In: Goodman J, Dennis DT, Sonenshine D, ed. Tick-borne Diseases of Humans. Washington: ASM Press, 2005:363-391.

Camacho, AT, Pallas, E, Gestal, JJ, Guitián FJ, et al. Ixodes hexagonus is the main candidate as vector of Theileria annae in northwest Spain. Vet Parasitol 2003; 112:157-163.

Caporale, DA, Rich, SM, Spielman, A, Telford, SR 3rd, et al. Discriminating between Ixodes ticks by means of mitochondrial DNA sequences. Mol Phylogenet Evol 1995; 4:361-365.

Casati, S, Bernasconi, MV, Gern, L, Piffaretti, JC. Assessment of intraspecific mtDNA variability of European Ixodes ricinus sensu stricto (Acari: Ixodidae). Infect Genet Evol 2008; 8:152-158.

Chitimia, L, Lin, RQ, Cosoroaba, I, Braila, P, et al. Molecular characterization of hard and soft ticks from Romania by sequences of the internal transcribed spacers of ribosomal DNA. Parasitol Res 2009; 105:907-911.

Dautel, H, Dippel, C, Oehme, R, Hartelt, K, Schettler, E. Evidence for an increased geographical distribution of Dermacentor reticulatus in Germany and detection of Rickettsia sp. RpA4. Int J Med Microbiol 2006; 296, Suppl 40:149-156.

Dergousoff, SJ, Chilton, NB. Differentiation of three species of ixodid tick, Dermacentor andersoni, $D$. variabilis and $D$. albipictus, by PCR-based approaches using markers in ribosomal DNA. Mol Cell Probes 2007; 21:343-348.

Estrada-Pena, A. Tick-borne pathogens, transmission rates and climate change. Front Biosci 2009; 14:2674-2687. 
Fukunaga, M, Yabuki, M, Hamase, A, Oliver, JH, Jr., et al. Molecular phylogenetic analysis of ixodid ticks based on the ribosomal DNA spacer, internal transcribed spacer 2, sequences. J Parasitol 2000; 86:38-43.

Gray, JS, Dautel, H, Estrada-Peña, A, Kahl, O, et al. Effects of climate change on ticks and tick-borne diseases in Europe. Interdiscip Perspect Infect Dis 2009; 2009:593232.

Jääskeläinen, AE, Tikkakoski, T, Uzcátegui, NY, Alekseev, AN, et al. Siberian subtype tick-borne encephalitis virus, Finland. Emerg Infect Dis 2006; 12:1568-1571.

Keirans, JE, Litwak, TR. Pictorial key to the adults of hard ticks, family Ixodidae (Ixodida: Ixodoidea), east of the Mississippi River. J Med Entomol 1989; 26:435-448.

Kolonin, GV. World Distribution of Ixodid Ticks (Genus Ixodes). Moskau: Nauka, 1981.

Mangold, AJ, Bargues, MD, Mas-Coma, S. 18S rRNA gene sequences and phylogenetic relationships of European hard-tick species (Acari: Ixodidae). Parasitol Res 1998; 84:31-37.

Masuzawa, T, Kharitonenkov, IG, Kadosaka, T, Hashimoto, N, et al. Characterization of Borrelia

burgdorferi sensu lato isolated in Moscow province-a sympatric region for Ixodes ricinus and Ixodes persulcatus. Int J Med Microbiol 2005; 294:455-464.

Murrell, A, Campbell, NJ, Barker, SC. Recurrent gains and losses of large (84-109 bp) repeats in the rDNA internal transcribed spacer 2 (ITS2) of rhipicephaline ticks. Insect Mol Biol 2001a; 10:587-596. Murrell, A, Campbell, NJ, Barker, SC. A total-evidence phylogeny of ticks provides insights into the evolution of life cycles and biogeography. Mol Phylogenet Evol 2001b; 21:244-258.

Murrell, A, Campbell, NJ, Barker, SC. The value of idiosyncratic markers and changes to conserved tRNA sequences from the mitochondrial genome of hard ticks (Acari: Ixodida: Ixodidae) for phylogenetic inference. Syst Biol 2003; 52:296-310.

Nava, S, Guglielmone, AA, Mangold, AJ. An overview of systematics and evolution of ticks. Front Biosci 2009; 14:2857-2877.

Nijhof, AM, Bodaan, C, Postigo, M, Nieuwenhuijs, $\mathrm{H}$, et al. Ticks and associated pathogens collected from domestic animals in the Netherlands. Vector Borne Zoonot Dis 2007; 7:585-595.

Pietzsch, ME, Mitchell, R, Jameson, LJ, Morgan, C, et al. Preliminary evaluation of exotic tick species and exotic pathogens imported on migratory birds into the British Isles. Vet Parasitol 2008; 155:328332.

Pomerantzev, BI. Fauna of U.S.S.R. Arachnida Ixodid ticks (Ixodidae). Am Inst Biol Sci 1959; IV:3843.

Poucher, KL, Hutcheson, HJ, Keirans, JE, Durden, LA, et al. Molecular genetic key for the identification of 17 Ixodes species of the United States (Acari:Ixodidae): a methods model. J Parasitol 1999; 85:623-629.

Schwarz, A, Maier, WA, Kistemann, T, Kampen, H. Analysis of the distribution of the tick Ixodes ricinus L. (Acari: Ixodidae) in a nature reserve of western Germany using Geographic Information Systems. Int J Hyg Environ Health 2009; 212:87-96.

Shao, R, Barker, SC, Mitani, H, Aoki, Y, Fukunaga, M. Evolution of duplicate control regions in the mitochondrial genomes of metazoa: a case study with Australasian Ixodes ticks. Mol Biol Evol 2005; 22:620-629.

Shone, SM, Dillon, HJ, Hom, SS, Delgado, N. A novel real-time PCR assay for the speciation of medically important ticks. Vector Borne Zoonot Dis 2006; 6:152-160.

Sonenshine, D. Biology of Ticks, Vol. 1. New York: Oxford University Press, 1991.

Wesson, DM, McLain, DK, Oliver, JH, Piesman, J, et al. Investigation of the validity of species status of Ixodes dammini (Acari: Ixodidae) using rDNA. Proc Natl Acad Sci USA 1993; 90:10221-10225. Zahler, M, Gothe, R, Rinder, H. Genetic evidence against a morphologically suggestive conspecificity of Dermacentor reticulatus and D. marginatus (Acari:Ixodidae). Int J Parasitol 1995; 25:1413-1419. 


\section{Tables and Figures}

Table 1. Primers and Polymerase Chain Reactions

\begin{tabular}{|c|c|c|c|c|c|c|c|}
\hline $\begin{array}{l}P C R \\
\text { numeration } \\
\text { no. }\end{array}$ & PCR purpose & $\begin{array}{c}\text { Primer } \\
\text { name }\end{array}$ & Primer sequence $\left(5^{\prime}-3^{\prime}\right)$ & Comments on primer ${ }^{\varepsilon}$ & $\begin{array}{c}\text { Optimal } P C R \\
\text { annealing } \\
\text { temperature }\left({ }^{\circ} \mathrm{C}\right)\end{array}$ & \begin{tabular}{|l|} 
Tested $P C R$ annealing \\
temperatures $\left({ }^{\circ} \mathrm{C}\right)^{\underline{1}}$
\end{tabular} & Amplicon length (bp) \\
\hline \multirow[t]{2}{*}{1} & Amplification of the entire ITS2 & ditT29 & CCTTCCCGTGGCTTCGTCTGT & $\begin{array}{l}\text { Nonspecific, targets near } \\
\text { the } 3^{\prime} \text { end of } 5 \mathrm{~S} \text { rRNA } \\
\text { gene }\end{array}$ & 58.1 & $52,55,57,58,60$ & $\begin{array}{c}\text { Near } 778 \text { for ixodes sp.; near } \\
1045 \text { for Dermacentor } \\
\text { reticulatus }\end{array}$ \\
\hline & & IITS800 & GGGGGTTGTCTCGCCTGATGT & $\begin{array}{l}\text { Nonspecific, targets near } \\
\text { the } 5^{\prime} \text { end of } 285 \text { rRNA } \\
\text { gene }\end{array}$ & & & \\
\hline \multirow[t]{2}{*}{2} & Specific for ixodes ricinus & dITS678 & CGTGTGTACAACAACACTTTCGA & Specific for 1 , ricinus & 51.9 & 52 & 137 \\
\hline & & rITS814 & TATGCTTAAATTCAGGGGGTTGTC & 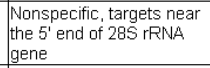 & & & \\
\hline \multirow[t]{2}{*}{$2 a$} & Specific for I. ricinus & dITS555 & TGCGTCGTAGCCTTCCGTCAGTC & TNonspecific & 55.7 & $55,57,58$ & 200 \\
\hline & & rITS754 & GCGCTTICCAAACAAAAACTTTGA & Specific for $/$, ricinus & & & \\
\hline \multirow[t]{2}{*}{3} & Specific for /xodes persulcatus & dITS118 & TGGGCAGCACGCATTITI & Nonspecific & 55.6 & 55,57 & 319 \\
\hline & & IITS436 & TGTACATCCGTCCATTTAGGC & Specific for l. persulcatus & & & \\
\hline \multirow[t]{2}{*}{4} & Specific for Ixodes hexagonus & dITSh277 & GGCCGCCGTTGGGATTTAC & Specific for I hexagonus & 56.2 & $56,57,58$ & 146 \\
\hline & & rITSh422 & ACAACATCGCCCCAACAAACAGAO & Specific for $!$ hexagonus & & & \\
\hline \multirow[t]{2}{*}{5} & $\begin{array}{l}\text { Amplification of a } \\
\text { mitochondrial } 16 \mathrm{~S} \text { rRNA } \\
\text { gene fragment }\end{array}$ & $16 \mathrm{Sa}$ & CGCCTGTTATCAAAAACAT & nonspecific & 46 & 46,50 & 509 \\
\hline & & $16 \mathrm{Sb}$ & CTCCGGTTGAACTCAGATC & nonspecific & & & \\
\hline
\end{tabular}

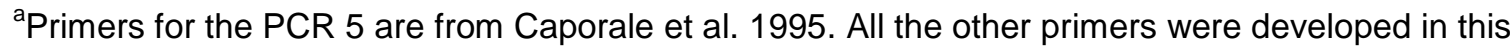
work.

${ }^{b}$ The first " $d$ " in the names of the primers indicates the direct primer; the first " $r$ " indicates the reverse primer. "Direct" is defined as collinear with the direction of the rRNA genes (Fig. 1).

"Nonspecific" means that the primer can also prime on DNA of one or more of the other ticks. The primers target within ITS2 locus if not otherwise indicated in the table.

${ }^{\mathrm{d}}$ All tested annealing temperatures yield the expected amplicon (other temperatures were not tested).

PCR, polymerase chain reaction. 
Figure 1. Structure of the ribosomal RNA gene cluster (rRNA cluster) and the parts of the multiple alignment of ITS2 of Ixodes ricinus and Ixodes persulcatus isolates used for design of the speciesspecific primers. Arrows indicate primers (not shown to scale); numbers near the arrows indicate primer pair numbered as in Table 1. The size of the rRNA gene cluster elements is close to that typical for Ixodes ticks. The exact length of the 28S rRNA gene is not known, but it is significantly larger than that of the 18S rRNA gene. The names of the primers are shown in Table 1.

Transcription (transcription product - 45S RNA which is then processed)

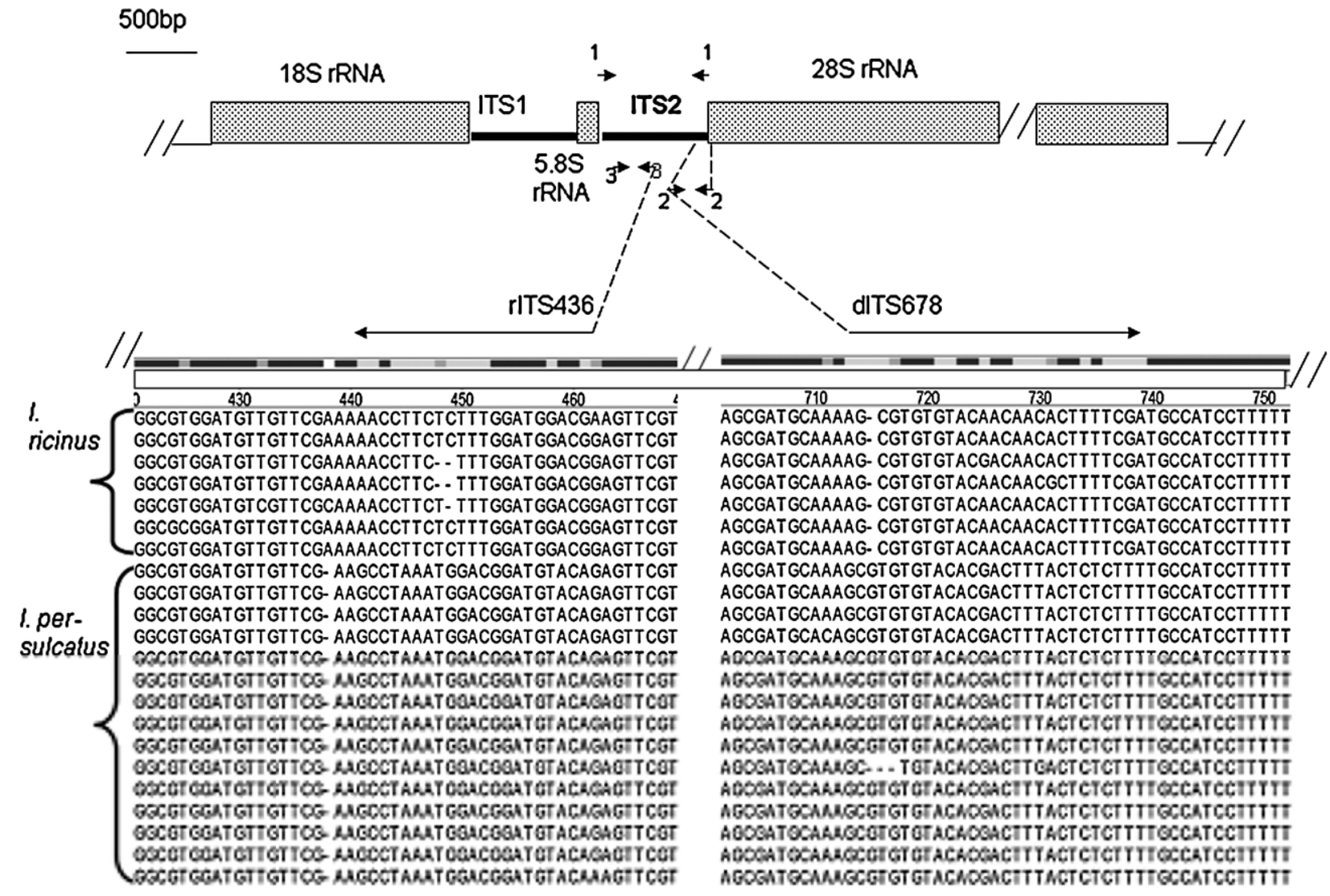


Figure 2. Agarose gel electrophoresis of polymerase chain reactions (PCRs): ric, I. ricinus; per, $I$. persulcatus; hex, Ixodes hexagonus; ret, Dermacentor reticulatus; M, DNA size marker (100 bp ladder). PCR numeration is shown in Table 1.

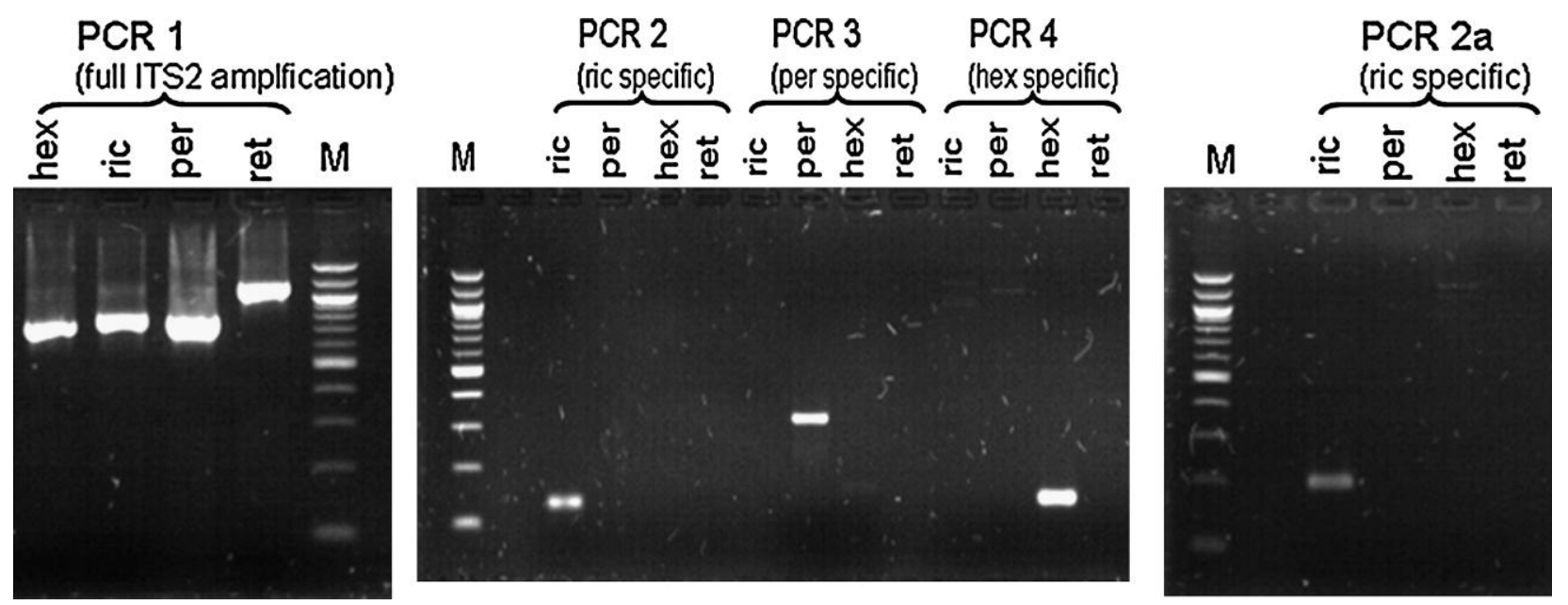

